\title{
Artificial sweeteners in food and beverage products at school
}

\author{
Rebecca M Schermbeck ${ }^{1, *}$, Julien Leider ${ }^{1}$, Elizabeth Piekarz-Porter ${ }^{1}$ and Jamie F Chriqui ${ }^{1,2}$ \\ 'Institute for Health Research and Policy, University of Illinois at Chicago, 1747 W. Roosevelt Road, M/C 275, Room \\ 558, Chicago, IL 60608, USA: ${ }^{2}$ Division of Health Policy and Administration, School of Public Health, University of \\ Illinois at Chicago, Chicago, IL, USA
}

Submitted 21 December 2017: Final revision received 16 April 2018: Accepted 24 April 2018: First published online 10 September 2018

\begin{abstract}
Objective: Experts recommend that products containing artificial sweeteners are not marketed to children or sold at schools. The present study aimed to provide a baseline assessment of the extent to which state laws and local school district wellness policies (LWP) address restrictions on the use of artificial sweeteners in competitive foods and beverages (CF\&B) sold at schools.

Design: A descriptive, cross-sectional study of policies in place for the 2014-15 school year.

Setting: Data were collected on laws in all fifty states and Washington, DC. LWP were compiled for 496/518 school food authorities (SFA) for which data were collected as part of the US Department of Agriculture's School Nutrition and Meal Cost Study.

Subjects: State laws and LWP respectively were coded on a $0-3$ ordinal scale for the strength of their restrictions on artificial sweeteners in CF\&B sold in each of five CF\&B venues, separately by grade level. Prevalence of state laws and LWP for SFA nationwide was computed.

Results: Thirteen states addressed the use of artificial sweeteners. Six states addressed the use of artificial sweeteners in both CF\&B. District-level artificial sweetener policies were most frequently addressed for beverages in elementary schools' vending machines. District policies also were more likely to address artificial sweeteners in states with laws addressing artificial sweeteners.

Conclusions: Most state laws and LWP do not address artificial sweeteners in CF\&B. This is not surprising given the Food and Drug Administration has approved eight artificial sweeteners for consumption and the Smart Snacks regulation does not limit artificial sweeteners for CF\&B.
\end{abstract}

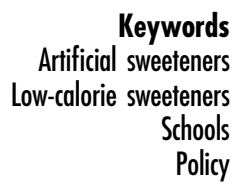

Artificial sweeteners, also known as high-intensity sweeteners, low-calorie sweeteners, non-caloric sweeteners, intense sweeteners and non-nutritive sweeteners, are often used in combination with or as a substitute for sugar in foods and beverages because they contribute large amounts of sweetness with little to no energy ${ }^{(1,2)}$. The Food and Drug Administration (FDA) regulates the artificial sweeteners introduced as ingredients in food and beverage products. As of now, eight high-intensity sweeteners (saccharin, aspartame, acesulfame potassium, sucralose, neotame, advantame, stevia plant extract, Luo Han Guo extract) are approved by the $\mathrm{FDA}^{(2,3)}$ as safe for human consumption. The Acceptable Daily Intake, determined by the FDA, is the amount of artificial sweetener safe to consume in milligrams per kilogram of body weight per day (Table 1$)^{(2)}$. According to the Academy of Nutrition and Dietetics, 'a 40-pound child would need to eat twenty-four packets of aspartame or drink four 12ounce cans of diet soda every day to reach this level ${ }^{(4)}$. Artificial sweeteners are found in consumable products beyond diet or low-calorie beverages, although the latter are the most commonly identified ${ }^{(5)}$ and consumed sources $^{(6)}$ of artificial sweeteners. Artificial sweeteners are also present in food products that are favourites of children and adolescents such as yoghurts, canned and dried fruit, granola bars, salad dressing and dips, bakery products, candy and ice cream ${ }^{(1,6)}$.

There are health benefits and concerns with artificial sweetener consumption for both adults and children. In adults, the consumption of artificial sweeteners can help reduce added sugar intake in the diet ${ }^{(1,7)}$ and has been linked with positive diabetes management ${ }^{(8)}$ and weight loss ${ }^{(9)}$. However, artificial sweetener consumption has also been linked with weight gain ${ }^{(10-14)}$, metabolic syndrome ${ }^{(11,15)}$ and 
Table 1 Acceptable Daily Intake (ADI) of artificial sweeteners approved by the Federal Drug Administration (adapted from https://www.fda.gov/Food/IngredientsPackagingLabeling/FoodAdditivesIngredients/ucm397725. htm\#SummaryTable)

\begin{tabular}{lcc}
\hline Artificial sweetener & ADI (mg/kg body weight per d) & $\begin{array}{c}\text { Number of tabletop sweetener } \\
\text { packets equivalent to ADI† }\end{array}$ \\
\hline Acesulfame potassium & 15 & 23 \\
Advantame & $32 \cdot 8$ & 4920 \\
Aspartame & 50 & 75 \\
Neotame & $0 \cdot 3$ & 23 \\
Saccharin & 15 & 45 \\
Luo Han Guo & Not specified & Not specified \\
Steviol glycoside (stevia) & 4 & 9 \\
Sucralose & 5 & 23
\end{tabular}

†Based on the amount a $60 \mathrm{~kg}(132 \mathrm{lb})$ person would need to consume to reach the ADI. Calculations assume a packet of high-intensity sweetener is equal two teaspoons of sugar in sweetness.

type 2 diabetes ${ }^{(11,14,15)}$ in adults. Literature reviews of artificial sweetener consumption and health outcomes share the same conclusion that there is insufficient evidence to encourage or discourage the use of artificial sweeteners for adults ${ }^{(16-18)}$.

Some researchers have examined the dietary purchasing and intake patterns of those who purchase or report consuming artificially sweetened beverages. One study analysed purchasing data from the Homescan longitudinal data set for 2000-2010 and the dietary intake from the National Health and Nutrition Examination Survey (NHANES) 20032010. Researchers reported that purchasing sweetened beverages (sugar-sweetened or artificially sweetened) exposes households to poor dietary purchasing and dietary intake patterns ${ }^{(19)}$. Another study used data from NHANES 2003-2012 waves to assess the diet quality of a nationally representative sample of over 22500 adults. Those who consumed artificially sweetened beverages consumed more energy from foods that are low in nutrition but high in added sugars and energy than those who did not drink artificially sweetened beverages ${ }^{(20)}$.

The research conducted with children on artificial sweetener consumption is limited and also inconclusive. In a review of the literature conducted by Archibald et al., it was reported that early exposure to artificial sweeteners may negatively impact body composition and cardiovascular health but that additional research is needed ${ }^{(21)}$. Research on how artificial sweeteners influence weight status and associated indicators like BMI vary from aiding in weight $\operatorname{loss}^{(22,23)}$ to having no impact on weight ${ }^{(24-28)}$ to causing weight gain $^{(29-34)}$ in children and adolescents. Artificial sweetener consumption for children and metabolic syndrome onset have not been well studied to date ${ }^{(27)}$.

Public consumption of food and beverage products containing artificial sweeteners is increasing for both adults and children ${ }^{(35-39)}$. Sylvetsky et al. reported a $200 \%$ increase in artificial sweetener consumption for children from 2009-2012 NHANES data ${ }^{(40)}$ compared with 19992000 NHANES data ${ }^{(37)}$. Artificial sweetener consumption increase is of interest since Mennella ${ }^{(41)}$ suggests that the consumption of sweet foods, even energy-free foods, presents a problem for children because it is at this life stage that children are developing the preference for sweet that will translate into long-term preferences and consumption decisions. Sylvetsky et al. found that saccharin, sucralose and acesulfame potassium were present in breast milk of lactating mothers and presumably ingested by their infant ${ }^{(42)}$. There is recent evidence suggesting that women who consume artificial sweeteners while pregnant have larger babies and this weight is carried into childhood ${ }^{(43,44)}$; and animal studies show that prenatal exposure to artificial sweeteners leads to an increased consumption of sweetened foods by the offspring later in life ${ }^{(45)}$.

Federal agencies and scientific organizations do not have a unified position on artificial sweetener consumption for children and/or adolescents. Many of the recommendations are not written specific to children and/or adolescents. The Academy for Nutrition and Dietetics ${ }^{(7)}$, the American Diabetes Association ${ }^{(46)}$, the American Heart Association ${ }^{(47)}$ and Healthy Eating Research ${ }^{(48)}$ acknowledge that the FDA has approved a number of artificial sweeteners for consumption and these can be used as part of a healthy eating plan to decrease added energy from sugar and add variety to the diet for the general population.

Guidelines and recommendations written specifically for children are more restrictive and cautious. The WHO recommends that beverages containing artificial sweeteners not be marketed to children ${ }^{(49)}$. The Pan American Health Organization's Nutrient Profile Model recommends that that any 'ultra-processed' food or beverage, which would include food and beverage products that contain any amount of artificial sweetener, not be marketed to children or found in the school environment, with the rationale being that the regular consumption of sweet food and beverage products (sugar-based or not) by children will promote the aforementioned intake and influence lifelong consumption patterns ${ }^{(50)}$. The National Academy of Sciences recommends that only high-school students be allowed to purchase beverages with artificial sweeteners on school property after the end of the school day and does not recommend foods with artificial sweeteners at all for students due to the lack of long-term evidence of safety 
when consumption begins in childhood ${ }^{(51)}$. The American Academy of Pediatrics calls for more research to show safety for children over time ${ }^{(52)}$. Finally, the Dietary Guidelines for Americans 2015 recommends for the public to reduce added sugar intake; noting that there may be short-term weight reduction by replacing added sugars with artificial sweeteners but it may not be effective in the long term ${ }^{(53)}$. The 2015 Dietary Guidelines Advisory Committee in the 2015 Scientific Report acknowledges that the recommendation to reduce added sugars may have unintentionally encouraged consumers and manufacturers to replace added sugars with artificial sweeteners. The Dietary Guidelines Advisory Committee goes on to state that added sugars should be reduced in the diet but not replaced with artificial sweeteners ${ }^{(54)}$.

In July 2014, federal nutrition standards for all foods and beverages sold and served outside school meals, referred to as 'Smart Snacks', took effect ${ }^{(55)}$. Smart Snacks establishes nutrition standards for foods and beverages sold or served on campus outside the school meal programme during school hours, henceforth known as competitive foods and beverages (CF\&B). The Smart Snacks regulation is extremely detailed addressing various nutrition components of CF\&B, including but not limited to sugars. Foods must have less than or equal to $35 \%$ of weight from total sugars served. For the 2014-15 school year elementary and middle schools can only sell plain water, $100 \%$ fruit/vegetable juice, $100 \%$ fruit/ vegetable juice diluted with water but no caloric sweeteners, low-fat unflavoured milk, or fat-free flavoured or unflavoured milk. High schools are allowed to also sell other flavoured and/or carbonated low-calorie beverages that would include beverages sweetened with artificial sweeteners ${ }^{(55)}$. Otherwise, states and districts have the option to address the use of artificial sweeteners in CF\&B ${ }^{(56)}$.

Although the FDA has deemed a number of artificial sweeteners as safe ${ }^{(2,3)}$, consumption by children raises concerns from health professionals and the general public ${ }^{(11,12,40,51,57-59)}$. The research is inconclusive as to whether artificial sweetener consumption assists in maintaining a healthful weight status, especially for children. Globally and nationally recognized health organizations such as the WHO, the Pan American Health Organization, the National Academy of Sciences and the American Academy of Pediatrics recommend food and beverage products containing artificial sweeteners not be marketed to children and adolescents or available for sale at school to children in elementary or middle school until further research is available related to consumption during childhood and long-term health and safety implications ${ }^{(49-52)}$. The objective of the present study was to provide a baseline assessment of the extent to which state laws and school district wellness policies for school food authorities (SFA) nationwide address restrictions on the use of artificial sweeteners in CF\&B.

\section{Methods}

On-the-books school district wellness policies and related state laws were collected as part of the National Wellness Policy Study. State statutes and administrative regulations, as well as any non-codified nutrition standards incorporated by reference into the state law, were collected for all fifty states and the District of Columbia using the subscription-based LexisNexis (www.advance.lexis.com) and Westlaw (www.next.westlaw.com) services, and collection was verified against publicly available secondary sources when possible ${ }^{(60-64)}$. District wellness policies were collected by Internet research with telephone followup using established methods ${ }^{(64)}$. District policies were collected for public SFA that participated in the National School Lunch Program and were included in the US Department of Agriculture's School Nutrition and Meal Cost Study (SNMCS) ${ }^{(64)}$. District wellness policies were able to be obtained for 496 of the 518 SFA for which SNMCS included data, located in forty-six states and the District of Columbia. Policies were collected for the 201415 school year and reflect district policies and state laws in effect as of the day after Labor Day 2014, which was used as a proxy for the beginning of the school year. Because the present study was a documentary research study of on-the-books, codified state laws and district wellness policies, no human subjects were involved and so it was not subject to institutional review board approval. District characteristics were obtained from the National Center for Education Statistics Common Core of Data ${ }^{(65-67)}$. These characteristics included the racial/ethnic distribution of grade 1-12 students, the percentage of students eligible for free and reduced-price lunch (used as a proxy for socioeconomic status (SES)), locale, district size measured by student enrolment in pre-kindergarten through 12 th grade, and Census region.

All state laws and district wellness policies related to artificial sweeteners were coded separately by grade level of applicability (elementary, middle or high school) according to the five venues where CF\&B can be sold or given away outside the school meal programme: vending machines, school stores, à la carte, class parties and fundraisers. Two variables were used to determine if a policy addressed limiting the use of artificial sweeteners in CF\&B, one for food and a second for beverages. The policy was coded as a ' 0 ' if there was no mention of the restriction; ' 1 ' if a restriction was mentioned but not required, was required only for a percentage of food/beverage products or was time- or location-specific; '2' if food/beverage products with artificial sweeteners were definitely restricted; and ' 3 ' if there was a CF\&B ban. For the purposes of Figs 1 and 2, states that had ' 0 ' coded for all venues in all grade levels were considered to have no restrictions on artificial sweeteners in CF\&B; states that had any venue in any grade level coded as a ' 1 ' were considered to have suggested or weak restrictions on artificial sweeteners in 
CF\&B; states that had any venue in any grade level coded as a ' 2 ' were considered to have definitive limits or restrictions on artificial sweeteners in CF\&B; and states that had any venue in any grade level coded as a ' 3 ' were considered to have a CF\&B ban.

All analyses were performed in the statistical software package Stata/SE version 13.1. Frequencies were computed showing the prevalence of artificial sweetener provisions in state law. Due to the nature of the sample being based on the complex SNMCS SFA-level survey design, weighted percentages with linearized standard errors were computed to illustrate the prevalence of artificial sweetener provisions in district policies for SFA nationwide. The weighted data were adjusted for SNMCS SFA-level non-response, but not district wellness policy collection non-response. (For interested readers, unweighted data are presented in the online supplementary material, Supplemental Table 1.) SFA-level percentages across all grades were computed by treating each grade level as a separate observation (i.e. each district policy for an SFA would be associated with three observations, one for each grade level). Multivariate logistic regressions accounting for the survey design and weights were computed to examine whether district-level artificial sweetener policies were more likely in states with artificial sweetener policies, adjusted for district-level majority race, free/reduced-price lunch eligibility, locale, district size and Census region.

\section{Results}

Table 2 presents data on the characteristics of the districts whose policies were included in the study. Districts were majority ( $\geq 66 \%$ ) White (65.4\%) followed by multi-racial/ other $(19 \cdot 2 \%)$. There were slightly more districts of medium SES $(38.7 \%)$ than low SES $(30.0 \%)$ or high SES (31.3\%). Most districts were described as small (55.3\%), rural (45.3\%) and Midwestern (40.0\%).

As of school year 2014-15, only six states' laws (AR, DC, IN, MA, RI and TX) addressed artificial sweeteners for both CF\&B. Nine states' laws (AR, DC, IN, MA, NC, NM, RI, TX and WV) addressed artificial sweeteners in competitive foods (CF; Fig. 1). Ten states' laws (AR, CA, CT, DC, IN, LA, $\mathrm{MA}, \mathrm{OH}, \mathrm{RI}$ and TX) addressed artificial sweeteners in competitive beverages (CB; Fig. 2). State laws were more likely to address artificial sweeteners in $\mathrm{CB}$ than in $\mathrm{CF}$. Roughly, twice as many states' laws addressed artificial sweeteners specifically (not through a CF\&B ban) for CB $(n 7)$ than CF $(n$ )

Table 3 presents data on the district-level restrictions for artificial sweeteners in CF\&B for each venue by grade level. Across all districts and grade levels, only $23.9 \%$ of the districts' wellness policies addressed any restrictions on artificial sweeteners for CF or CB (data not shown). Consistent with the state laws, artificial sweetener restrictions were more commonly addressed in district policies governing CB (as compared with CF) and for elementary schools (as compared with middle and high schools). District policy restrictions on artificial sweeteners in beverages were most likely to be suggested, or limits that did not apply at all times ('suggested restriction' in Table 3). Across all grade levels, district policy restrictions on artificial sweeteners in beverages were most commonly addressed for vending machines (20.0 (SE 1.5) \%); school stores (16.3 (sE 1.3) \%) and à la carte lines (16.0 (sE 1.3) \%). In contrast, in each venue at most $11 \%$ of all district policies addressed restrictions on artificial sweeteners in

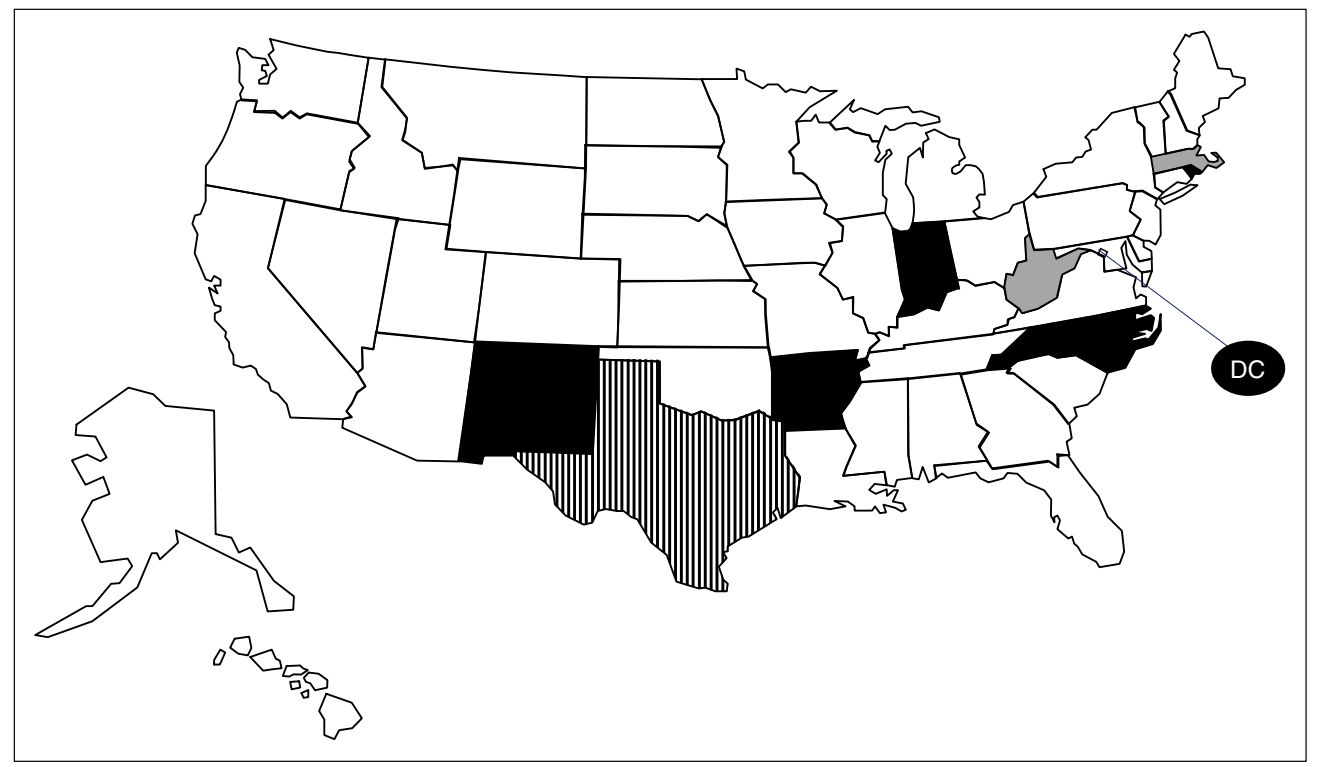

Fig. 1 US states that addressed artificial sweetener use in competitive foods, 2014-15 school year ( $\square$, competitive food ban, $n 6$; $\square$, definitive limits or restrictions, $n 2$; II, suggested or weak restrictions, $n 1$; $\square$, no restrictions, $n$ 42) 


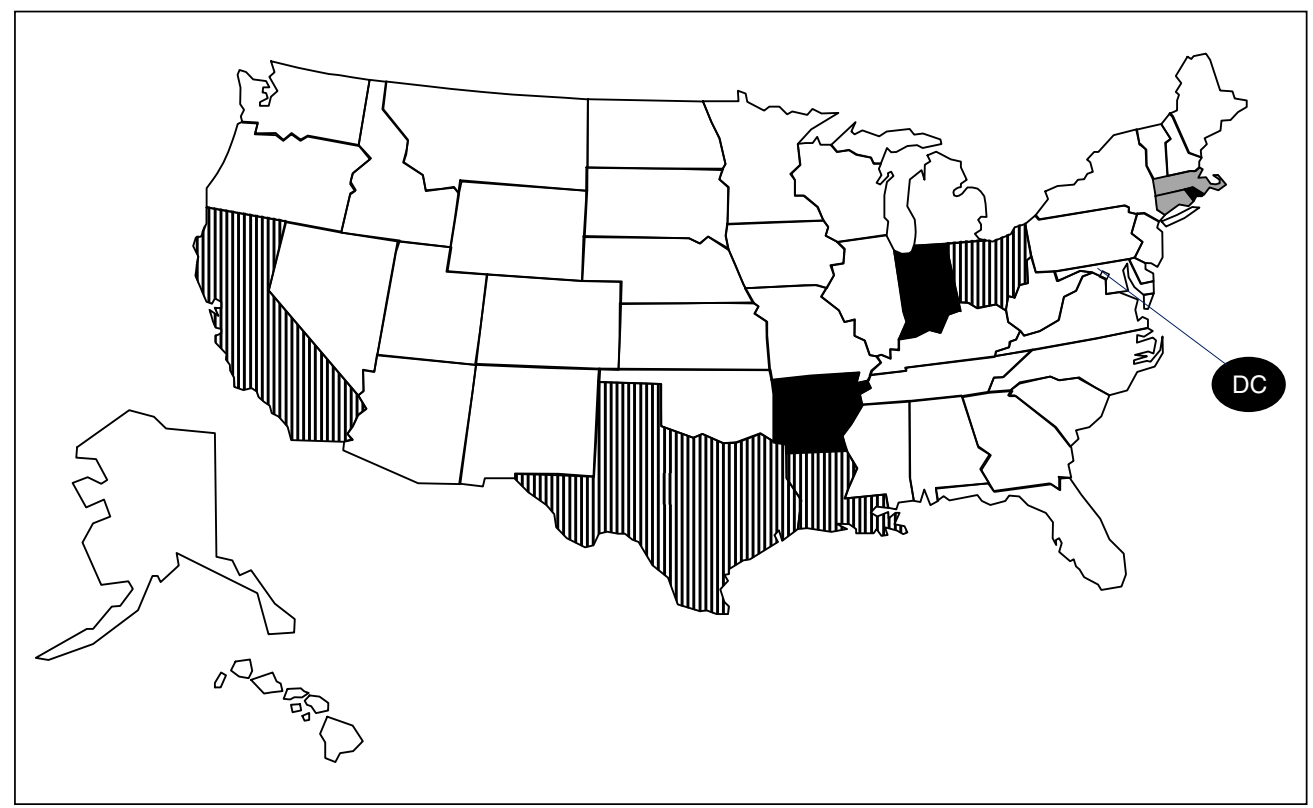

Fig. 2 US states that addressed artificial sweetener use in competitive beverages, 2014-15 school year ( $\square$, competitive beverage ban, $n 4$; $\square$, definitive limits or restrictions, $n 2$; 而, suggested or weak restrictions, $n 4$; $\square$, no restrictions, $n$ 41)

Table 2 Characteristics of the district sample from all fifty states and Washington, DC, USA, 2014-15 school year (496 local school districts) $\dagger$

\begin{tabular}{|c|c|}
\hline Characteristic & $\%$ \\
\hline \multicolumn{2}{|l|}{ Race/ethnicity } \\
\hline Majority White ( $\geq 66 \%$ ) & $65 \cdot 4$ \\
\hline Majority African-American ( $\geq 50 \%$ ) & $7 \cdot 1$ \\
\hline Majority Hispanic/Latino ( $\geq 50 \%)$ & 8.3 \\
\hline Multi-racial/Other & $19 \cdot 2$ \\
\hline \multicolumn{2}{|l|}{ Socio-economic status (SES) } \\
\hline Low SES (>60.20\% FPL) & $30 \cdot 0$ \\
\hline Medium SES (>39.72-60.20\% FPL) & 38.7 \\
\hline High SES $(\leq 39.72 \%$ FPL $)$ & $31 \cdot 3$ \\
\hline \multicolumn{2}{|l|}{ Locale } \\
\hline Urban (large- to mid-size city) & $13 \cdot 0$ \\
\hline Suburb & $21 \cdot 3$ \\
\hline Rural & $45 \cdot 3$ \\
\hline Township & $20 \cdot 4$ \\
\hline \multicolumn{2}{|l|}{ School district size } \\
\hline Small ( $\leq 1437$ students) & $55 \cdot 3$ \\
\hline Medium (1438-5655 students) & 31.6 \\
\hline Large ( $\geq 5656$ students) & 13.0 \\
\hline \multicolumn{2}{|l|}{ Region } \\
\hline West & $16 \cdot 0$ \\
\hline Midwest & $40 \cdot 0$ \\
\hline South & $25 \cdot 7$ \\
\hline Northeast & $18 \cdot 3$ \\
\hline
\end{tabular}

FPL, federal poverty level.

tn 471-496 due to item-specific missing data. Items may not total $100 \%$ due to rounding. Weighted percentages are shown.

$\mathrm{CF}$ and, for the most part, such restrictions were by virtue of a CF ban in elementary schools as opposed to a suggested or definitive restriction on artificial sweeteners in CF sold in schools (Table 3).

Finally, across all venues and in any grade level, the percentage of all districts with policies addressing artificial sweeteners in CF was $27 \cdot 8 \%$, while $20 \cdot 6 \%$ of all districts were located in a state with a law addressing artificial sweeteners in CF (data not shown). The prevalence of artificial sweetener policies governing $\mathrm{CB}$ in any grade level of applicability or venue was somewhat higher than for $\mathrm{CF}$ : $37.3 \%$ of district policies addressed artificial sweeteners in CB and $35.1 \%$ of districts were located in a state with a law addressing artificial sweeteners in CB (data not shown). Table 4 presents results of multivariate logistic regressions examining the relationship between district and state artificial sweetener-related policies and laws, respectively, across all grade levels and locations of sale of CF\&B. The adjusted prevalence of district artificial sweetener-related policies governing foods was $76 \cdot 2 \%$ with a state law as compared with only $14.9 \%$ without a relevant state law. Similarly, the adjusted prevalence of district artificial sweetener policies governing beverages was $72.5 \%$ with a state law $v$. only $17.9 \%$ without a state law. (Adjusted OR and 95\% CI are presented in Table 4.) We found a similar association with state law CF\&B bans (data not shown) but there were no significant associations with any of the sociodemographic controls.

\section{Discussion}

To the authors' knowledge, the present paper is the first to report on restrictions for artificial sweeteners in CF\&B in state law and local school district policies for SFA nationwide. There are three main points this baseline assessment of restrictions for artificial sweeteners in CF\&B in state law and local school district policies has produced. First, few states (thirteen states) and local wellness policies $(23.9 \%$ of district policies for all grades) address any restrictions on the use of artificial sweeteners in CF\&B. The lack of 
Table 3 Percentage of district wellness policies for school food authorities nationwide restricting artificial sweeteners in competitive foods and beverages (CF\&B), by venue and grade level, all fifty states and Washington, DC, USA, 2014-15 school year (496 local school districts)†

\begin{tabular}{|c|c|c|c|c|c|c|c|c|c|c|c|c|c|c|c|c|}
\hline & \multicolumn{8}{|c|}{ Foods } & \multicolumn{8}{|c|}{ Beverages } \\
\hline & \multicolumn{2}{|c|}{$\begin{array}{l}\text { Elementary } \\
\text { school }\end{array}$} & \multicolumn{2}{|c|}{$\begin{array}{l}\text { Middle } \\
\text { school }\end{array}$} & \multicolumn{2}{|c|}{$\begin{array}{l}\text { High } \\
\text { school }\end{array}$} & \multicolumn{2}{|c|}{$\begin{array}{l}\text { All } \\
\text { grades }\end{array}$} & \multicolumn{2}{|c|}{$\begin{array}{l}\text { Elementary } \\
\text { school }\end{array}$} & \multicolumn{2}{|c|}{$\begin{array}{l}\text { Middle } \\
\text { school }\end{array}$} & \multicolumn{2}{|c|}{$\begin{array}{l}\text { High } \\
\text { school }\end{array}$} & \multicolumn{2}{|c|}{$\begin{array}{c}\text { All } \\
\text { grades }\end{array}$} \\
\hline & $\%$ & SE & $\%$ & SE & $\%$ & $\mathrm{SE}$ & $\%$ & $\mathrm{SE}$ & $\%$ & SE & $\%$ & SE & $\%$ & SE & $\%$ & SE \\
\hline \multicolumn{17}{|l|}{ Vending machines } \\
\hline No restriction & $76 \cdot 8$ & 2.9 & $94 \cdot 9$ & $1 \cdot 2$ & $96 \cdot 4$ & 1.0 & 89.0 & $1 \cdot 2$ & $67 \cdot 3$ & 3.1 & $84 \cdot 4$ & $2 \cdot 1$ & 89.6 & 1.7 & $80 \cdot 0$ & 1.5 \\
\hline Any restriction & 23.2 & $2 \cdot 9$ & $5 \cdot 1$ & $1 \cdot 2$ & $3 \cdot 6$ & 1.0 & $11 \cdot 0$ & $1 \cdot 2$ & $32 \cdot 7$ & $3 \cdot 1$ & $15 \cdot 6$ & $2 \cdot 1$ & $10 \cdot 4$ & $1 \cdot 7$ & $20 \cdot 0$ & 1.5 \\
\hline Suggested restriction & $7 \cdot 1$ & 1.3 & 0.5 & $0 . \overline{4}$ & 0.5 & 0.4 & $2 \cdot 8$ & $0 . \overline{5}$ & $17 \cdot 3$ & $2 \cdot 0$ & 11.0 & 1.8 & $6 \cdot 8$ & 1.4 & 11.9 & 1.0 \\
\hline Definitive restriction & 1.7 & 0.5 & 1.8 & 0.5 & 1.9 & 0.6 & 1.8 & 0.3 & 1.7 & 0.5 & $2 \cdot 3$ & 0.7 & 2.5 & 0.8 & $2 \cdot 2$ & 0.4 \\
\hline CF\&B ban & $14 \cdot 4$ & $2 \cdot 8$ & 2.9 & 1.0 & 1.2 & 0.7 & $6 \cdot 4$ & $1 \cdot 1$ & $13 \cdot 8$ & $2 \cdot 7$ & $2 \cdot 4$ & 1.0 & $1 \cdot 1$ & 0.6 & $6 \cdot 0$ & 1.1 \\
\hline \multicolumn{17}{|l|}{ School stores } \\
\hline No restriction & $85 \cdot 8$ & 2.5 & $97 \cdot 7$ & 0.7 & 97.5 & 0.7 & 93.5 & 1.0 & $75 \cdot 3$ & $2 \cdot 8$ & $86 \cdot 4$ & 1.9 & $90 \cdot 3$ & 1.6 & 83.8 & 1.3 \\
\hline Any restriction & $14 \cdot 2$ & 2.5 & 2.3 & 0.7 & 2.5 & 0.7 & 6.5 & 1.0 & 24.7 & $2 \cdot 8$ & 13.6 & 1.9 & 9.7 & 1.6 & $16 \cdot 3$ & 1.3 \\
\hline Suggested restriction & $7 \cdot 1$ & 1.3 & 0.4 & 0.4 & 0.4 & 0.4 & $2 \cdot 7$ & 0.5 & $18 \cdot 1$ & $2 \cdot 1$ & $11 \cdot 1$ & 1.8 & $7 \cdot 0$ & 1.4 & $12 \cdot 3$ & 1.1 \\
\hline Definitive restriction & $1 \cdot 7$ & 0.5 & 1.8 & 0.5 & 1.9 & 0.6 & 1.8 & 0.3 & 1.7 & 0.5 & $2 \cdot 3$ & 0.7 & 2.5 & 0.8 & $2 \cdot 2$ & 0.4 \\
\hline CF\&B ban & 5.4 & $2 \cdot 2$ & 0.1 & 0.1 & $0 \cdot 1$ & 0.1 & $2 \cdot 0$ & 0.8 & 4.9 & $2 \cdot 2$ & $0 \cdot 1$ & 0.1 & $0 \cdot 1$ & 0.1 & 1.8 & 0.8 \\
\hline \multicolumn{17}{|l|}{ À la carte } \\
\hline No restriction & 87.8 & 2.6 & 95.3 & 1.2 & $96 \cdot 4$ & 1.0 & 93.0 & 1.1 & 78.3 & $2 \cdot 8$ & 84.7 & $2 \cdot 0$ & 89.6 & 1.6 & 84.0 & 1.3 \\
\hline Any restriction & $12 \cdot 3$ & $2 \cdot 6$ & 4.7 & $1 \cdot 2$ & $3 \cdot 6$ & 1.0 & $7 \cdot 0$ & $1 \cdot 1$ & $21 \cdot 7$ & $2 \cdot 8$ & $15 \cdot 3$ & $2 \cdot 0$ & $10 \cdot 5$ & 1.6 & $16 \cdot 0$ & 1.3 \\
\hline Suggested restriction & 1.4 & 0.6 & 0.5 & 0.4 & 0.6 & 0.5 & 0.9 & 0.3 & $11 \cdot 2$ & 1.8 & $10 \cdot 0$ & 1.7 & $6 \cdot 3$ & 1.3 & $9 \cdot 3$ & 0.9 \\
\hline Definitive restriction & 1.3 & 0.4 & 1.3 & 0.5 & 1.5 & 0.5 & 1.4 & 0.3 & $2 \cdot 3$ & 0.7 & 2.9 & 0.9 & $3 \cdot 2$ & 0.9 & $2 \cdot 8$ & 0.5 \\
\hline CF\&B ban & 9.5 & $2 \cdot 5$ & $2 \cdot 9$ & 1.0 & 1.6 & 0.7 & 4.8 & 1.0 & 8.2 & $2 \cdot 4$ & $2 \cdot 4$ & 0.9 & 1.0 & 0.4 & 4.0 & 1.0 \\
\hline \multicolumn{17}{|l|}{ Class parties } \\
\hline No restriction & $94 \cdot 8$ & $2 \cdot 2$ & 98.7 & 0.6 & $98 \cdot 6$ & 0.6 & $97 \cdot 3$ & 0.8 & 94.3 & $2 \cdot 2$ & $98 \cdot 1$ & 0.7 & 97.9 & 0.8 & $96 \cdot 7$ & 0.9 \\
\hline Any restriction & $5 \cdot 2$ & $2 \cdot \overline{2}$ & 1.3 & 0.6 & 1.4 & 0.6 & $2 \cdot 7$ & 0.8 & $5 \cdot 7$ & $2 \cdot 2$ & 1.9 & 0.7 & $2 \cdot 1$ & 0.8 & 3.3 & 0.9 \\
\hline Suggested restriction & 0.4 & 0.4 & 0.4 & 0.4 & 0.4 & 0.4 & 0.4 & 0.2 & $1 \cdot 2$ & 0.6 & 1.3 & 0.6 & 1.4 & 0.7 & 1.3 & 0.4 \\
\hline Definitive restriction & 0.7 & 0.4 & 0.7 & 0.4 & 0.8 & 0.4 & 0.7 & 0.2 & 0.5 & 0.3 & 0.5 & 0.3 & 0.6 & 0.3 & 0.5 & 0.2 \\
\hline CF\&B ban & $4 \cdot 1$ & $2 \cdot 1$ & 0.2 & 0.1 & 0.2 & 0.2 & 1.6 & 0.8 & 4.0 & $2 \cdot 1$ & $0 \cdot 1$ & 0.1 & $0 \cdot 1$ & 0.1 & 1.5 & 0.8 \\
\hline \multicolumn{17}{|l|}{ Fundraisers } \\
\hline No restriction & 91.1 & $2 \cdot 4$ & $96 \cdot 2$ & 1.0 & 95.9 & 1.0 & $94 \cdot 3$ & 1.0 & $85 \cdot 3$ & 2.6 & $90 \cdot 2$ & 1.6 & 92.5 & 1.4 & 89.2 & $1 \cdot 1$ \\
\hline Any restriction & 8.9 & $2 \cdot 4$ & 3.8 & 1.0 & 4.2 & 1.0 & $5 \cdot 7$ & 1.0 & 14.7 & 2.6 & $9 \cdot 8$ & 1.6 & 7.5 & 1.4 & $10 \cdot 8$ & $1 \cdot 1$ \\
\hline Suggested restriction & $0 \cdot 1$ & 0.0 & $0 \cdot 1$ & 0.0 & $0 \cdot 1$ & 0.1 & $0 \cdot 1$ & 0.0 & $6 \cdot 2$ & 1.3 & $6 \cdot 0$ & $1 \cdot 3$ & $3 \cdot 4$ & 0.9 & $5 \cdot 3$ & 0.7 \\
\hline Definitive restriction & 1.5 & 0.5 & 1.5 & 0.5 & 1.7 & 0.6 & 1.6 & 0.3 & 1.5 & 0.5 & 1.5 & 0.5 & 1.6 & 0.6 & 1.5 & 0.3 \\
\hline & $7 \cdot 4$ & 2.3 & $2 \cdot 3$ & 0.8 & $2 \cdot 4$ & 0.9 & $4 \cdot 1$ & 0.9 & 7.0 & 2.3 & $2 \cdot 3$ & 0.8 & 2.4 & 0.9 & 4.0 & 0.9 \\
\hline \multicolumn{17}{|l|}{ All venues } \\
\hline No restriction & $72 \cdot 3$ & 3.0 & $91 \cdot 3$ & 1.5 & $92 \cdot 9$ & 1.4 & $85 \cdot 2$ & $1 \cdot 3$ & 64.5 & $3 \cdot 1$ & $82 \cdot 3$ & $2 \cdot 1$ & $86 \cdot 3$ & 1.9 & $77 \cdot 3$ & 1.5 \\
\hline Any restriction & $27 \cdot 7$ & 3.0 & 8.7 & 1.5 & $7 \cdot 1$ & 1.4 & 14.8 & 1.3 & 35.6 & 3.1 & $17 \cdot 7$ & $2 \cdot 1$ & $13 \cdot 7$ & 1.9 & $22 \cdot 7$ & 1.5 \\
\hline
\end{tabular}

†Because not all districts had all grade levels, $n 482$ at the elementary school level, $n 472$ at the middle school level and $n 440$ at the high school level. Estimates for all grades are based on 1394 district-grade combinations. Tables may not total $100 \%$ due to rounding. Weighted percentages with survey-adjusted, linearized standard errors are shown. For interested readers, unweighted data are presented in the online supplementary material, Supplemental Table 1.

restrictions on artificial sweeteners in CF\&B could be due to a number of factors including but not limited to the FDA recognizing multiple artificial sweeteners as safe for consumption $^{(2,3)}$, many scientific organizations endorsing the use of artificial sweeteners as part of a healthy diet to reduce sugar intake $e^{(7,46-48)}$ and that restricting artificial sweeteners in CF\&B is not a requirement of the Smart Snacks standards ${ }^{(56)}$.

Second, policies are narrow in scope. Policies tend to focus on $\mathrm{CB}$ over $\mathrm{CF}$, younger grades over older grades, and are not inclusive of all venues. The emphasis on beverages may be due to public awareness campaigns ${ }^{(5)}$, public policies such as the Smart Snacks regulations ${ }^{(56)}$ and the work of various organizations, such as the WHO and the Centers for Disease Control and Prevention ${ }^{(68,69)}$, focused on reducing sugar-sweetened beverage intake, as well as efforts to enact sugar-sweetened beverage taxes ${ }^{(70,71)}$. Additionally, beverage products containing artificial sweeteners are more abundant ${ }^{(5)}$ and more often identified $^{(57)}$ than food products containing artificial sweeteners, potentially contributing to a greater prominence in state laws and district policy.

Moreover, when policies with restrictions on artificial sweeteners in CF\&B are written at the state or district level, it is most commonly for elementary-school student beverages followed by foods. Restrictions at the elementary level are more common for many areas of wellness ${ }^{(72)}$, not just restrictions on artificial sweeteners in CF\&B. Policies restricting artificial sweeteners in CF\&B are often not inclusive of all venues, specifically class parties and fundraisers, which is consistent with other literature ${ }^{(72)}$. These policies, if written, should be for the entire student body across all venues. Researchers ${ }^{(11,12,40,57,58)}$ and national organizations $^{(51,52,54)}$ are asking for more research to be initiated on artificial sweeteners because the long-term health implications for children and adults are unavailable.

As seen in other work ${ }^{(72-74)}$, when a state law is in place, adoption and implementation at the district level are 
Table 4 Multivariate logistic regression examining the relationship between state and district artificial sweetener-related policies, all fifty states and Washington, DC, USA, 2014-15 school year (471 local school districts)

\begin{tabular}{|c|c|c|c|c|c|c|}
\hline \multirow[b]{2}{*}{ Variable } & \multicolumn{3}{|c|}{ District artificial sweetener policy: foods } & \multicolumn{3}{|c|}{ District artificial sweetener policy: beverages } \\
\hline & AOR & $95 \% \mathrm{Cl}$ & Adj. prev. (\%) & AOR & $95 \% \mathrm{Cl}$ & Adj. prev. (\%) \\
\hline \multicolumn{7}{|l|}{ State law } \\
\hline No state law & 1.00 & Ref. & 14.94 & 1.00 & Ref. & 17.93 \\
\hline State law & $22 \cdot 10^{*}$ & $9.35,52 \cdot 23$ & $76 \cdot 20$ & $15 \cdot 09^{*}$ & $7.45,30.57$ & 72.45 \\
\hline \multicolumn{7}{|l|}{ Majority race } \\
\hline Majority White ( $\geq 66 \%$ ) & 1.00 & Ref. & 27.00 & 1.00 & Ref. & $36 \cdot 30$ \\
\hline Majority Black ( $\geq 50 \%)$ & $2 \cdot 25$ & $0.46,11.04$ & 38.26 & 2.04 & $0.51,8.15$ & 47.71 \\
\hline Majority Hispanic ( $\geq 50 \%)$ & 0.65 & $0.14,3.00$ & $22 \cdot 24$ & 1.13 & $0.33,3.86$ & 38.19 \\
\hline Multi-racial/Other & 1.19 & $0.45,3 \cdot 11$ & 29.12 & 1.02 & $0.47,2.23$ & 36.61 \\
\hline \multicolumn{7}{|l|}{ Socio-economic status (SES) } \\
\hline Low SES (>60.20\% FPL) & 1.25 & $0.44,3.59$ & $27 \cdot 60$ & 0.99 & $0.33,3.00$ & 33.46 \\
\hline Medium SES (>39.72-60.20\% FPL) & 1.51 & $0 \cdot 70,3 \cdot 26$ & 30.00 & 1.87 & $0.82,4.27$ & 43.17 \\
\hline High SES $(\leq 39.72 \%$ FPL $)$ & 1.00 & Ref. & 24.96 & 1.00 & Ref. & 33.58 \\
\hline \multicolumn{7}{|l|}{ Locale } \\
\hline Large-mid size city & 1.00 & Ref. & 29.97 & 1.00 & Ref. & $31 \cdot 10$ \\
\hline Suburban & 0.67 & $0.19,2 \cdot 29$ & $25 \cdot 02$ & 1.74 & $0.57,5 \cdot 26$ & 39.26 \\
\hline Rural & 0.75 & $0 \cdot 18,3 \cdot 19$ & $26 \cdot 40$ & 1.54 & $0.44,5.41$ & 37.43 \\
\hline Township & 1.24 & $0.31,4.87$ & 32.85 & 1.73 & $0.50,6.05$ & 39.22 \\
\hline \multicolumn{7}{|l|}{ District size } \\
\hline Small ( $\leq 1437$ students) & 1.03 & $0.34,3 \cdot 13$ & 28.64 & 0.71 & $0.27,1.88$ & $36 \cdot 62$ \\
\hline Medium (1438-5655 students) & 0.85 & $0.32,2.27$ & 26.32 & 0.70 & $0.30,1.65$ & 36.37 \\
\hline Large ( $\geq 5656$ students) & 1.00 & Ref. & 28.23 & 1.00 & Ref. & 41.90 \\
\hline \multicolumn{7}{|l|}{ Region } \\
\hline West & 1.00 & Ref. & 21.02 & 1.00 & Ref. & 38.20 \\
\hline Midwest & 1.66 & $0.53,5 \cdot 21$ & $27 \cdot 15$ & 0.50 & $0.21,1.18$ & 27.73 \\
\hline South & 2.78 & $0.92,8.40$ & 34.70 & 1.65 & $0.78,3.52$ & 46.51 \\
\hline Northeast & 1.28 & $0.32,5 \cdot 16$ & 23.88 & 1.47 & $0.55,3.97$ & 44.52 \\
\hline
\end{tabular}

AOR, adjusted odds ratio; Adj. prev., adjusted prevalence; FPL, federal poverty level; Ref., reference category.

${ }^{*}$ AOR was statistically significant: $P<0.001$.

more likely. This holds true for policies related to artificial sweeteners in CF\&B. While it is interesting to note that there are a handful of districts that have exceeded the expectations of the state and federal laws to include language restricting artificial sweeteners in foods and/or beverages, in most cases, districts are following states' lead with regard to regulating artificial sweeteners in CF\&B

Third, policies are written as suggestions or encouragement rather than as definitive restrictions on artificial sweeteners in CF\&B. It is important to remember that such a restriction is not a requirement of the Smart Snacks regulation $^{(56)}$ and there are eight high-intensity sweeteners that are approved as safe for human consumption by the $\mathrm{FDA}^{(2,3)}$. The fact that the most prevalent policies addressing artificial sweeteners other than CF\&B bans are suggested restrictions may imply that some districts may recognize the limited research available on the long-term impact of artificial sweetener consumption for children $^{(51,52,57)}$ but cannot justify a complete artificial sweetener ban because consumption of food and beverage products with artificial sweeteners is viewed as a method to reduce added sugars intake ${ }^{(7,46-48)}$.

Strengths of the current study include that it provides baseline data for future research in the area of artificial sweeteners in CF\&B. The results of the study come from a nationwide sample of district wellness policies and include a review of all state laws on the subject. Limitations of the study are that this research does not identify how or if these policies are being implemented at the school level and that the data are from the 2014-15 school year (last year of available data). Future studies should continue to monitor artificial sweetener policies at the state and district levels, particularly if federal regulations or guidelines change in this regard.

\section{Conclusion}

In conclusion, the current research shows that artificial sweeteners in CF\&B is not commonly addressed in either state law or local wellness policies. When local wellness policies do address artificial sweeteners in CF\&B, they are most often beverages in elementary schools, the restrictions are written as suggestions or encouraged, and they are more common in states with laws that also address artificial sweeteners. The lack of definitive artificial sweetener-related requirements is not surprising given artificial sweeteners in CF\&B is not addressed in the Smart Snacks regulation ${ }^{(55,56)}$ and the FDA has approved eight high-intensity sweeteners for human consumption ${ }^{(2,3)}$. Continued monitoring of state law and local wellness policies with regard to restrictions on artificial sweeteners in CF\&B needs to be conducted in tandem with research to address the long-term safety and health implications of regular consumption of artificial sweeteners as research is limited and inconclusive. 


\section{Acknowledgements}

Financial support: Funding for this study was provided as part of the US Department of Agriculture School Wellness Policy Cooperative Agreement (USDA-FNS-OSP-SWP-15IL-01). The US Department of Agriculture had no role in the design, analysis or writing of this article. Conflict of Interest: None. Authorship: R.M.S. developed the research question, and wrote the introduction, results and discussion sections; J.L. performed the statistical analysis and wrote the methods section; E.P.-P. assisted in drafting and editing the manuscript; J.F.C. assisted in framing, drafting and editing the manuscript. Ethics of human subject participation: Because this was a documentary research study of on-the-books, codified state laws and district wellness policies, no human subjects were involved and so the study was not subject to institutional review board approval.

\section{Supplementary material}

To view supplementary material for this article, please visit https://doi.org/10.1017/S136898001800143X

\section{References}

1. Gardner C, Wylie-Rosett J, Gidding SS et al. (2012) Nonnutritive sweeteners: current use and health perspectives: a scientific statement from the American Heart Association and the American Diabetes Association. Diabetes Care 35, $1798-1808$.

2. US Food and Drug Administration (2018) Additional Information About High-Intensity Sweeteners Permitted For Use in Food in the United States. https://www.fda.gov/Food/ IngredientsPackagingLabeling/FoodAdditivesIngredients/ ucm397725.htm (accessed April 2018).

3. US Food and Drug Administration (2014) High-Intensity Sweeteners. https://www.fda.gov/food/ingredientspack aginglabeling/foodadditivesingredients/ucm397716.htm (accessed December 2017).

4. Ansel K (2017) Are Artificial Sweeteners Safe For Kids? http://www.eatright.org/resource/food/nutrition/nutritionfacts-and-food-labels/the-inside-scoop-on-artificial-sweeteners (accessed December 2017).

5. Popkin BM, Kenan WR \& Hawkes C (2016) The sweetening of the global diet, particularly beverages: patterns, trends and policy responses for diabetes prevention. Lancet Diabetes Endocrinol 4, 174-186.

6. Ng SW, Slining MM \& Popkin BM (2012) Use of caloric and noncaloric sweeteners in US consumer packaged foods, 2005-2009. J Acad Nutr Diet 112, 1828-1834.

7. Fitch C \& Keim KS (2012) Position of the Academy of Nutrition and Dietetics: use of nutritive and nonnutritive sweeteners. J Acad Nutr Diet 112, 739-758.

8. Anton SD, Martin CK, Han H et al. (2010) Effects of stevia, aspartame, and sucrose on food intake, satiety, and postprandial glucose and insulin levels. Appetite 55, 37-43.

9. Peters JC, Wyatt HR, Foster GD et al. (2014) The effects of water and non-nutritive sweetened beverages on weight loss during a 12-week weight loss treatment program. Obesity (Silver Spring) 22, 1415-1421.
10. Parker DR, Gonzalez S, Derby CA et al. (1997) Dietary factors in relation to weight change among men and women from two southeastern New England communities. Int $J$ Obes Relat Metab Disord 21, 103-109.

11. Pepino MY (2015) Metabolic effects of non-nutritive sweeteners. Physiol Behav 152, 450-455.

12. Fowler SP, Williams K, Resendez RG et al. (2008) Fueling the obesity epidemic? Artificially sweetened beverage use and long-term weight gain. Obesity (Silver Spring) 16, 1894-1900.

13. Stellman SD \& Garfinkel L (1986) Artificial sweetener use and one-year weight change among women. Prev Med 15, 195-202.

14. Schulze MB, Manson JE, Ludwig DS et al. (2004) Sugarsweetened beverages, weight gain, and incidence of type 2 diabetes in young and middle-aged women. JAMA $\mathbf{2 9 2}$, 927-934.

15. Nettleton JA, Lutsey PL, Wang Y et al. (2009) Diet soda intake and risk of incident metabolic syndrome and type 2 diabetes in the multi-ethnic study of atherosclerosis (MESA). Diabetes Care 32, 688-694.

16. Lohner S, Toews I \& Meerpohl JJ (2017) Health outcomes of non-nutritive sweeteners: analysis of the research landscape. Nutr J 16, 55.

17. Azad MB, Abou-Setta AM, Chauhan BF et al. (2017) Nonnutritive sweeteners and cardiometabolic health: a systematic review and meta-analysis of randomized controlled trials and prospective cohort studies. CMAJ 189, E929-E939.

18. Shankar P, Ahuja S \& Sriram K (2013) Non-nutritive sweeteners: review and update. Nutrition 29, 1293-1299.

19. Piernas C, Mendez MA, Ng SW et al. (2014) Low-calorieand calorie-sweetened beverages: diet quality, food intake, and purchase patterns of US household consumers. Am J Clin Nutr 99, 567-577.

20. An R (2016) Beverage consumption in relation to discretionary food intake and diet quality among US adults, 2003 to 2012. J Acad Nutr Diet 116, 28-37.

21. Archibald AJ, Dolinsky VW \& Azad MB (2018) Early-life exposure to non-nutritive sweeteners and the developmental origins of childhood obesity: global evidence from human and rodent studies. Nutrients 10, E194.

22. Ludwig DS, Peterson KE \& Gortmaker SL (2001) Relation between consumption of sugar-sweetened drinks and childhood obesity: a prospective, observational analysis. Lancet 357, 505-508.

23. de Ruyter JC, Olthof MR, Seidell JC et al. (2012) A trial of sugar-free or sugar-sweetened beverages and body weight in children. N Engl J Med 367, 1397-1406.

24. Kral TVE, Stunkard AJ, Berkowitz RI et al. (2008) Beverage consumption patterns of children born at different risk of obesity. Obesity (Silver Spring) 16, 1802-1808.

25. O'Connor TM, Yang S \& Nicklas TA (2006) Beverage intake among preschool children and its effect on weight status. Pediatrics 118, e1010-e1018.

26. Ebbeling CB, Feldman HA, Osganian SK et al. (2006) Effects of decreasing sugar-sweetened beverage consumption on body weight in adolescents: a randomized, controlled pilot study. Pediatrics 117, 673-680.

27. Williams CL, Strobino BA \& Brotanek J (2007) Weight control among obese adolescents: a pilot study. Int J Food Sci Nutr 58, 217-230.

28. Ebbeling CB, Feldman HA, Chomitz VR et al. (2012) A randomized trial of sugar-sweetened beverages and adolescent body weight. N Engl J Med 367, 1407-1416.

29. Blum JW, Jacobsen DJ \& Donnelly JE (2005) Beverage consumption patterns in elementary school aged children across a two-year period. J Am Coll Nutr 24, 93.

30. Berkey CS, Rockett HRH, Field AE et al. (2004) Sugar-added beverages and adolescent weight change. Obesity (Silver Spring) 12, 778-788. 
31. Johnson L, Mander AP, Jones LR et al. (2007) Is sugarsweetened beverage consumption associated with increased fatness in children? Nutrition 23, 557-563.

32. Forshee RA \& Storey ML (2003) Total beverage consumption and beverage choices among children and adolescents. Int J Food Sci Nutr 54, 297-307.

33. Giammattei J, Blix G, Marshak HH et al. (2003) Television watching and soft drink consumption: associations with obesity in 11- to 13-year-old schoolchildren. Arch Pediatr Adolesc Med 157, 882-886.

34. Vanselow MS, Pereira MA, Neumark-Sztainer D et al. (2009) Adolescent beverage habits and changes in weight over time: findings from Project EAT. Am J Clin Nutr 90, 1489-1495.

35. Piernas C, Ng SW \& Popkin B (2013) Trends in purchases and intake of foods and beverages containing caloric and low-calorie sweeteners over the last decade in the United States. Pediatr Obes 8, 294-306.

36. Mattes RD \& Popkin BM (2009) Nonnutritive sweetener consumption in humans: effects on appetite and food intake and their putative mechanisms. Am J Clin Nutr 89, 1-14.

37. Sylvetsky AC, Welsh JA, Brown RJ et al. (2012) Low-calorie sweetener consumption is increasing in the United States. Am J Clin Nutr 96, 640-646.

38. Drewnowski A \& Rehm CD (2015) Socio-demographic correlates and trends in low-calorie sweetener use among adults in the United States from 1999 to 2008. Eur J Clin Nutr 69, 1035-1041.

39. Fakhouri THI, Kit BK \& Ogden CL (2012) Consumption of diet drinks in the United States, 2009-2010. NCHS Data Brief issue 109, 1-8.

40. Sylvetsky AC, Jin Y, Clark EJ et al. (2017) Consumption of low-calorie sweeteners among children and adults in the United States. I Acad Nutr Diet 117, 441-448.e2.

41. Mennella JA (2014) Ontogeny of taste preferences: basic biology and implications for health. Am J Clin Nutr 99, issue 3, 704S-711S.

42. Sylvetsky AC, Gardner AL, Bauman V et al. (2015) Nonnutritive sweeteners in breast milk. J Toxicol Environ Health A 78, 1029-1032.

43. Azad MB, Sharma AK, de Souza RJ et al. (2016) Association between artificially sweetened beverage consumption during pregnancy and infant body mass index. JAMA Pediatr 170, 662-670.

44. Zhu Y, Olsen SF, Mendola P et al. (2017) Maternal consumption of artificially sweetened beverages during pregnancy, and offspring growth through 7 years of age: a prospective cohort study. Int J Epidemiol 46, 1499-1508.

45. von Poser Toigo E, Huffell AP, Mota CS et al. (2015) Metabolic and feeding behavior alterations provoked by prenatal exposure to aspartame. Appetite 87, 68-174.

46. American Diabetes Association (2014) Low-Calorie Sweeteners. http://www.diabetes.org/food-and-fitness/food/ what-can-i-eat/understanding-carbohydrates/artificialsweeteners/ (accessed December 2018).

47. American Heart Association (2014) Non-Nutritive Sweeteners (Artificial Sweeteners). http://www.heart.org/HEARTORG/ HealthyLiving/HealthyEating/Nutrition/Non-Nutritive-Sweet eners-Artificial-Sweeteners_UCM_305880_Article.jsp\# . WfIzYWhSyM8 (accessed December 2017).

48. Healthy Eating Research (2013) Recommendations for Healthier Beverages. http://www.healthyeatingresearch.org/ research/recommendations-for-healthier-beverages (accessed December 2017).

49. World Health Organization (2015) WHO Regional Office for Europe nutrient profile model (2015). http://www.euro.who. int/en/health-topics/disease-prevention/nutrition/publications/ 2015/who-regional-office-for-europe-nutrient-profile-model2015 (accessed June 2018).

50. Pan American Health Organization (2016) Pan American Health Organization Nutrient Profile Model. http://www. paho.org/hq/index.php?option=com_content\&view $=$ article \&id=11662\%3Apaho-nutrient-profile-model\&catid $=1370 \%$ 3Anutrition-general\&Itemid $=41739 \&$ lang $=$ en $\quad$ (accessed December 2017).

51. Institute of Medicine (2007) Nutrition Standards for Foods in Schools: Leading the Way Toward Healthier Youth. Washington, DC: The National Academy Press.

52. Murray R \& Bhatia J (2015) Snacks, sweetened beverages, added sugars, and schools. Pediatrics 135, 575-583.

53. US Department of Health and Human Services \& US Department of Agriculture (2015) Dietary Guidelines for Americans 2015-2020, 8th ed. http://www.health.gov/ dietaryguidelines/2015/guidelines/ (accessed December 2017).

54. Dietary Guidelines Advisory Committee (2015) Scientific Report of the 2015 Dietary Guidelines Advisory Committee. https://health.gov/dietaryguidelines/2015-scientific-report/ (accessed June 2018).

55. Food and Nutrition Service, US Department of Agriculture (2013) National School Lunch Program and School Breakfast Program: nutrition standards for all foods sold in school as required by the Healthy, HungerFree Kids Act of 2010. Interim final rule. Fed Regist $\mathbf{7 8}$, 39067-39120.

56. Food and Nutrition Service, US Department of Agriculture (2016) National School Lunch Program and School Breakfast Program: nutrition standards for all foods sold in school as required by the Healthy, Hunger-Free Kids Act of 2010. Final rule and interim final rule. Fed Regist 81, 50131-50151.

57. Sylvetsky AC, Greenberg M, Zhao X et al. (2014) What parents think about giving nonnutritive sweeteners to their children: a pilot study. Int J Pediatr 2014, 819872.

58. Bruyère O, Ahmed SH, Atlan C et al. (2015) Erratum to: Review of the nutritional benefits and risks related to intense sweeteners. Arch Public Health 73, 41-51.

59. Agüero SD, Dávila LA, Escobar Contreras MC et al. (2018) Noncaloric sweeteners in children: a controversial theme. BioMed Res Int 2018, 4806534

60. National Cancer Institute (2014) Classification of Laws Associated with School Students. (CLASS). http://class. cancer.gov/ (accessed December 2017).

61. National Conference of State Legislatures (2014) Childhood Obesity: Update of Legislative Policy Options. http://www. ncsl.org/issues-research/health/childhood-obesity-2014. aspx (accessed December 2017).

62. National Association of State Boards of Education (2014) State School Health Policy Database. http://nasbe.org/ healthy_schools/hs/index.php (accessed December 2017).

63. Centers for Disease Control and Prevention (2012) Competitive Foods and Beverages in US Schools: A State Policy Analysis. https://www.cdc.gov/healthyyouth/ nutrition/pdf/compfoodsbooklet.pdf (accessed December 2017).

64. Mathematica Policy Research (2018) School Nutrition and Meal Cost Study (SNMCS): 2013-2017. https://www. mathematica-mpr.com/our-publications-and-findings/projects/ school-nutrition-and-meal-cost-study (accessed June 2018).

65. US Department of Education, National Center for Education Statistics, Common Core of Data (2015) Local Education Agency (School District) Universe Survey Data: 2013-2014 v.1a. https://nces.ed.gov/ccd/pubagency.asp (accessed December 2017)

66. US Department of Education, National Center for Education Statistics, Common Core of Data (2015) Public Elementary/ Secondary School Universe Survey Data: 2013-2014, v.1a. https://nces.ed.gov/ccd/pubschuniv.asp (accessed December 2017).

67. US Department of Education, National Center for Education Statistics, Common Core of Data (2014) Private School 
Universe Survey Data: 2011-12. https://nces.ed.gov/surveys/ pss/ (accessed June 2018).

68. World Health Organization (2016) Reducing consumption of sugar-sweetened beverages to reduce the risk of childhood overweight and obesity. http://www.who.int/elena/titles/ ssbs_childhood_obesity/en (accessed December 2017).

69. Centers for Disease Control and Prevention (2010) The CDC guide to strategies for reducing the consumption of sugarsweetened beverages. https://stacks.cdc.gov/view/cdc/ 51532 (accessed June 2018).

70. Chaloupka FJ, Powell LM \& Chriqui JF (2009) SugarSweetened Beverage Taxes and Public Health. http:// healthyeatingresearch.org/research/sugar-sweetened-beveragetaxes-and-public-health-a-research-brief/ (accessed December 2017).

71. Powell LM, Chriqui JF, Khan T et al. (2013) Assessing the potential effectiveness of food and beverage taxes and subsidies for improving public health: a systematic review of prices, demand and body weight outcomes. Obes Rev 14, 110-128.

72. Piekarz E, Schermbeck R, Young SK et al. (2016) School District Wellness Policies: Evaluating Progress and Potential for Improving Children's Health Eight Years After the Federal Mandate. School Years 2006-07 Through 2013-14. Volume 4. Chicago, IL: Bridging the Gap Program and the National Wellness Policy Study, Institute for Health Research and Policy, University of Illinois at Chicago.

73. Turner L, Chriqui JF \& Chaloupka FJ (2013) Classroom parties in US elementary schools: the potential for policies to reduce student exposure to sugary foods and beverages. J Nutr Educ Behav 45, 611-619.

74. Taber DR, Chriqui JF \& Chaloupka FJ (2012) Association and diffusion of nutrition and physical activity policies on the state and district level. J Sch Health 82, 201-209. 